\title{
Typal Intelligent DSS for Making Strategic Decisions in the Energy Sector and Examples of Application Based on Agent-Service Approach
}

\author{
Liudmila V. Massel \\ Melentiev Energy Systems Institute of Siberian Branch of \\ the Russian Academy of Sciences \\ Irkutsk, Russia \\ e-mail:massel@isem.irk.ru
}

\author{
Vladimir R. Kuzmin \\ Melentiev Energy Systems Institute of Siberian Branch of \\ the Russian Academy of Sciences \\ Irkutsk, Russia \\ e-mail: kuzmin_vr@isem.irk.ru
}

\begin{abstract}
This article briefly considers concept of situational management, proposed by D.A. Pospelov and common scheme for solving the situational management problem is provided. As a result of the mapping of the common scheme for solving the situational management problem on the tools of semantic modeling and expert systems, an architecture of typal intelligent DSS for making strategic decisions was proposed. Description of agent-service approach is given and implementation of two DSS based on this typal architecture is shown. Brief description of Contingency Management Language (CML) and Knowledge Manipulation Language (KML) is given.
\end{abstract}

Keywords-intelligent decision support system; agentservice approach; multi-agent system; situational management.

\section{INTRODUCTION}

Currently, the concept of intelligent energy systems is spreading in Russia [1, 2]. Also, since 2017, the program of digital transformation of energy is being considered as a part of the program "Digital economy" [3, 4]. However, implementation of this concept, requires, on the one hand - development and utilization of modern information technologies for management of technological infrastructure, and, on the other hand - modernization of the infrastructure itself. Infrastructure modernization is tightly bond with strategic decision-making for energy sector development, and requires, in turn, intellectualization of tools for support of these decisions.

At Information technologies laboratory of ESI SB RAS, an approach was developed, based on development of situational management concept for creation of intelligent environment for strategic decision-making support. Main methods of this approach are situational analysis and situational modelling. To implement them, it was suggested to use methods of semantic modelling (ontological, cognitive, event and probabilistic, based on Bayesian network) [5].

As a result of the mapping of the common scheme for solving the situational management problem proposed by Pospelov, on the tools of semantic modeling and expert systems, an architecture of typal intelligent DSS for making strategic decisions was proposed. Two implementations of the architecture are suggested: 1) "Situation polygon", integrating tools of semantic modelling and visual analytics; 2) Weboriented information system for impact assessment of energy on region's geoecology. This article considers situational management and its basic concepts, typal architecture of intelligent DSS for making strategic decisions, description of agent-service approach is provided. Examples of applications based on typal architecture and agent-service approach are shown.

\section{SitUATIONAL MANAGEMENT}

Situational management as a scientific direction was founded by D.A. Pospelov and was developed by him and his students and colleagues in the 80s of last century [6]. Pospelov considered the situational management, semiotic modeling, semiotic management, logical-linguistic management methods as close concepts, because, in his interpretation, they are all based on the concept of a situation, classification of situations and their transformation.

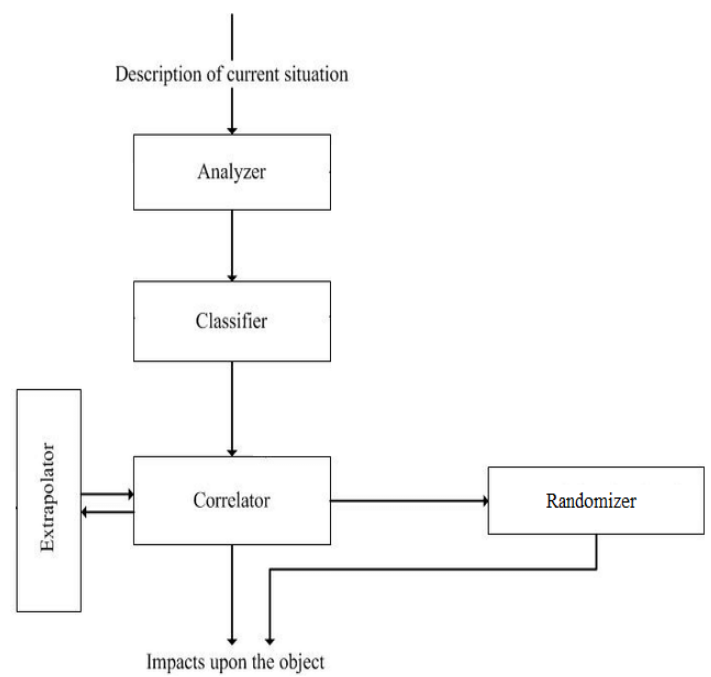

Fig. 1. Common scheme for solving the situational management problem 
Common scheme for solving the situational management problem is shown in Fig. 1.

According to Pospelov, common scheme of situational management includes the following blocks: Analyzer, Classifier, Correlator, Extrapolator, and Randomizer. They perform the following functions: Analyzer - evaluates messages and determines the need for the management system to intervene in the process taking place in the object; Classifier - uses the information stored in it, relates the current situation to one or more classes that correspond to one-step solutions; Correlator - defines the logical-transformer rule (LTR) that should be used. If there are several suitable LTRs, the Correlator uses the Extrapolator, which selects the best LTR from those selected by the Correlator based on a forecast of possible situations. If the decision can't be made, then Randomizer is triggered and one of the actions that won't have too much effect on the object is selected, or the system refuses any effect.

\section{ARCHITECTURE OF TYPAL INTELLIGENT DSS FOR MAKING STRATEGIC DECISIONS}

As a result of the mapping of the common scheme for solving the situational management problem proposed by D.A. Pospelov, on the tools of semantic modeling and expert systems, an architecture of typal intelligent DSS of semiotic type for making strategic decisions was proposed. This architecture is pictured at fig. 2. To describe current situation, we will use Contingency Management Language (CML) or Knowledge Manipulation Language (KML). An expert system will be used for analysis of current situation. To classify situation, the expert system and authors' tools will be used such as OntoMap (support of ontological modelling) and CogMap (support of cognitive modelling). Correlator will be based on CogMap and Extrapolator will use probabilistic and event modelling (with the help of EventMap and BayNet tools). Mentioned tools already developed by the team of Information technologies laboratory of ESI SB RAS.

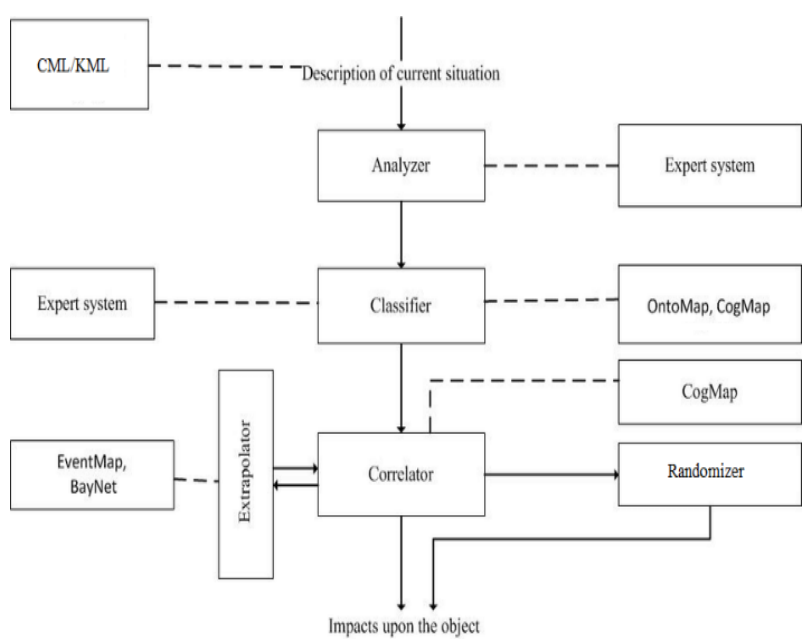

Fig. 2. Architecture of typal intelligent DSS of semiotic type for making strategic decisions
At the first stage, with the help of an expert system, an analysis of situations and determination of their belonging, for example, to some type of energy systems, grouping of situations by type, place, scale. Next, the task is to determine the correspondence rules $S \leftrightarrow M$, where $\{S\}$ is the set of situations, $\{M\}$ is the set of measures (control actions), given that the correspondence can be either single-valued or multivalued, for example, $S_{i} \leftrightarrow M_{1} \wedge M_{2} \ldots \wedge$ Mn. In addition, it is necessary to determine the structure of the set of event evaluations $\left\{V_{k}\right\}$, for example, the estimate is determined by the triple $(R, T, C)$, where $\mathrm{R}$ is the required resources, $\mathrm{T}$ is the time frame, $\mathrm{C}$ is the cost of the event. It is assumed that evaluations of events are formed in dialogue with an expert, as a result of which the knowledge base is filled.

\section{AGENT-SERVICE APPROACH}

Authors think, that it is necessary to provide a mathematical description of a methodical approach for the construction of multi-agent systems, before providing a description of usage of agent-service approach.

System is being created with a certain goal $G$, which should be clearly defined before start of development. This goal will be reached through accomplishing several tasks, both simple and complex, and these tasks can be divided into separate subtasks. It is necessary to define a set of all tasks $\{T\}$, and system must be able to solve them. Set of tasks will define a function set of the future system $\{F\}$. System's functions are divided between agents $\{A\}$ in such a way, that each agent solves its own task, or a part of larger task. So, it is required to make a chain of mappings: $G \rightarrow\{T\} \rightarrow\{F\} \rightarrow\{A\}$.

But actions must be taken in a specific order and part of tasks may be solved in a different way, so it is required to define an order of agents' call $\left\{P_{A}\right\}$. Using this order and agent set in the system, it is necessary to generate a set of agent scenarios $\left\{S_{A}\right\}$, for which it is required to create event models describing these scenarios $\left\{E_{S}\right\}$. To speed up MAS development, it is advisable to use basic software components for agents $\left\{C_{B}\right\}$. So, a model of multiagent system can be represented as:

$$
M_{M A S}=\left(A, P_{A}, S_{A}, E_{S}, C_{B}\right),
$$

where $A-$ set of agents, $P_{A}-$ agents' call order, $S_{A}$ - set of agents' scenarios, $E_{S}-$ set of event models, $C_{B}$ - set of basic components.

Based on this mathematical description, Galperov V.I. proposed a methodical approach for creating typical multi-agent systems. Basis of this approach is the method of design and implementation of typical multiagent system (MAS), which was implemented as a method. Full description of this method was given in [7], there will be listed only main steps:

- Description of the future system, based on the specifics of solved task, that includes: de termination of a goal of MAS creation, determination of set of tasks $\{T\}$, determination 
of set of MAS functions $\{F\}$, determination of a list of agents $\{A\}$ based on system's functions and development of MAS basic components, development of MAS basic components $\left\{C_{B}\right\}$.

- Development of agents' scenarios: determination of order of agents' call $\left\{P_{A}\right\}$, development of scenarios of agent calls $\left\{S_{A}\right\}$, description of scenarios in the form of event models $\left\{E_{S}\right\}$

- Development of MAS architecture

- Designing of MAS

- Implementation of MAS

Agent-service approach to development intelligent decision-making support "Situation polygon" is proposed due to following reasons:

- Full situation description requires creation of usage scenarios of different semantic and mathematical modelling tools

- Application of agent-service approach makes it relatively easy to add new modelling tools to the "Situation polygon"

- Some types of modelling require large and complicated calculations, which can be performed simultaneously. Agent-service approach allows to parallelize tasks and, by that, reduce calculation time

\section{EXAMPLES OF DSS BASED ON THE PROPOSED ARCHITECTURE}

Based on the proposed architecture of a typal intelligent DSS, two intelligent DSS for strategic decision-making are being developed:

- "Situational polygon" — IDSS for strategic decision-making for energy sector development.

- WIS - Web-oriented information and analytical system for impact assessment of energy on region's geoecology.

\section{A. "Situational polygon"}

This system is being developed based on an approach to supporting strategic decision-making, based on the use of the concept of situational management. Its architecture is presented on fig. 3. [8]

The main goal of creation of this system is to provide support of decision-making for an expert (or decision-maker). As for a set of tasks $\{\mathrm{T}\}$ we may define this list:

- Semantic modelling tools support

- Ability to transform one type of semantic model to another (e.g. from ontology to cognitive map)

- Work with knowledge bases, which includes both content and subsequent work with it search, editing knowledge, etc.
- Ability to visualize results, obtained from semantic modelling tools, using Geocomponent

- Work with database to provide the system's functioning. Database stores system's configurations, users' data and some models

To implement this set of tasks, team, represented, by the authors, develops Contingency Management Language (CML) [9], which appears to be the one of the main components of the system and provides functions such as knowledge description, interface functions and integration of other components. It will be discussed in the next section.

In accordance with the set of tasks, described above, the system must have a set of functions, which allows, to solve these tasks. From this, we can conclude that the following list of agents is required

- Main agent-coordinator - controls other coordinating agents, contains agent scenarios, which are used for call order of agentcoordinators, provides user's actions control $\left\{A_{\text {COORD }}\right\}$

- Agent-coordinator of database - provides access to the database $\left\{A_{D B}\right\}$

- Agent-coordinator of knowledge base provides access to the knowledge base $\left\{A_{K B}\right\}$

- Agent-coordinator of the semantic modelling tools - controls agents, which responsible for work of semantic modelling tools $\left\{A_{S M}\right\}$. Every tool is an agent too.

- Agent-coordinator of mathematical modelling tools - controls agents, which responsible for work of mathematical modelling tools $\left\{A_{M M}\right\}$. Every tool is an agent too.

- Agent-coordinator of visualization tools and Geocomponent - allow to visualize obtained results as an ontology, cognitive map or by using map services $\left\{A_{\text {GEOVIS }}\right\}$

Set of basic components $\left\{C_{B}\right\}$ includes these elements:

- Semantic modelling tools - OntoMap $\left(C_{O N T}\right)$, CogMap $\left(C_{C O G}\right)$, EventMap $\left(C_{E V E N T}\right)$, BayNet $\left(C_{B N}\right)$

- Expert system "Advice" that provides creation and usage of knowledge base

- Repositary, that stores semantic models and allow to work with them $\left(C_{R E P}\right)$

- Database - stores all system's information $\left(C_{D B}\right)$

- Geocomponent - displays obtained results using map services $\left(C_{G E O}\right)$ 


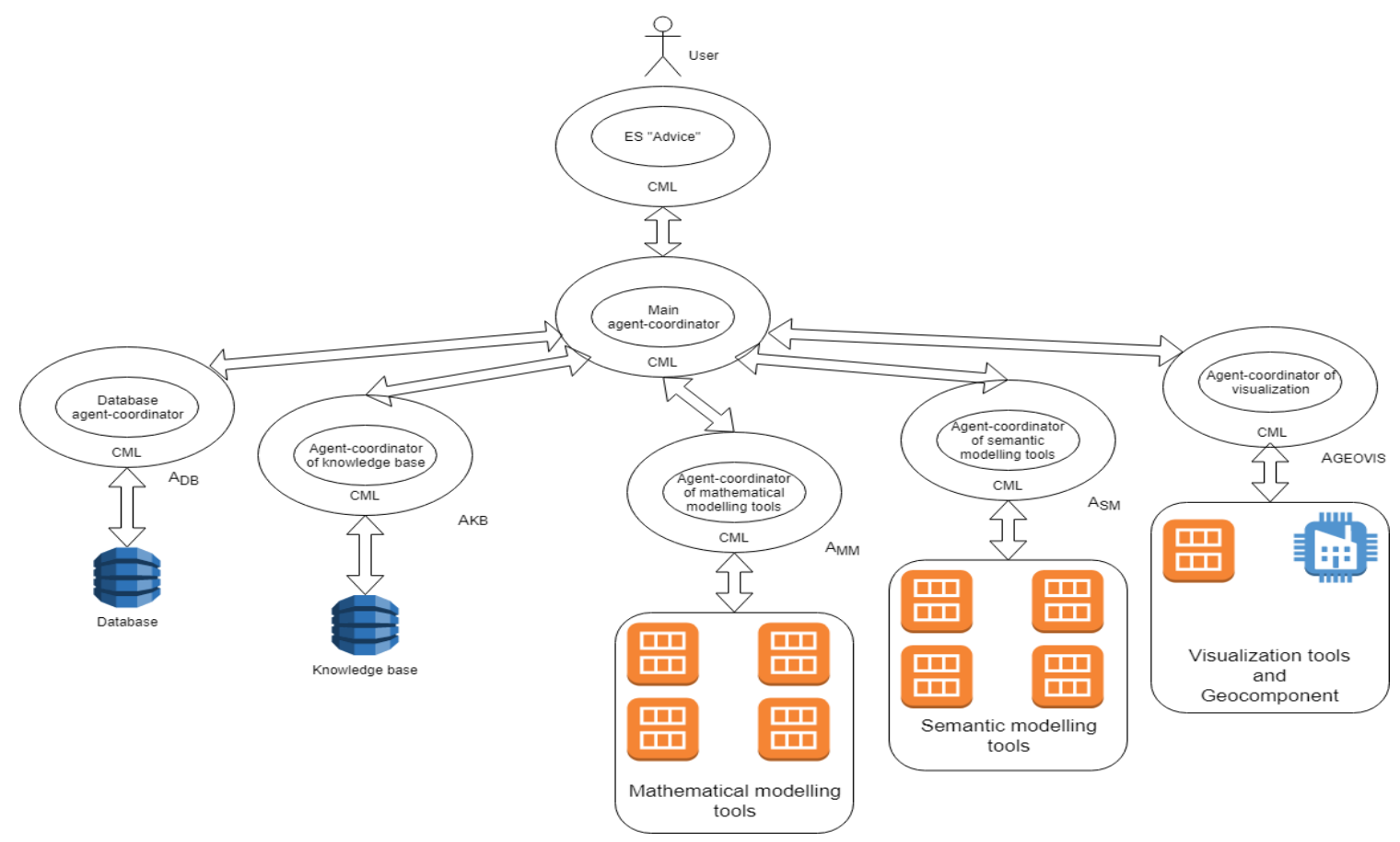

Fig. 3. Architecture of Situation polygon

\section{B. Web-oriented information and analytical system}

This system is based on integration of geoinformation system, mathematical and semantical modelling tools, tools for impact assessment of the energy sector on region's geoecology, databases and knowledgebase. Some of the system's components will be implemented using multiagent technology $[7,10]$.

According to the architecture, displayed in fig. 4 , system is divided in four layers:

- Layer of semantic modelling - contains semantic models for descriptions of factors connections, that determine the quality of life, considering anthropotechnical factors such as: impact of pollutants from energy companies on the environment and energy supply.

- Layer of mathematical modelling - contains programs, developed on the basis of selected methods and models, for calculating the amount of pollutants and their impact on the quality of life of the population, taking into account the capacity of energy facilities (energy supply) and population (population density) in the considered territory.

- Knowledge representation layer - contains knowledge base, that stores knowledge description for constructing semantic models, and an ontology system for describing knowledge of the subject domain; the latter can be used both for building a knowledge base and for designing a database.

- Data representation layer - integrates geoinformation system (GIS) and database, including geographic coordinates of energy facilities. GIS can be used both to illustrate the results of calculations, and for visual interpretation of semantic models.

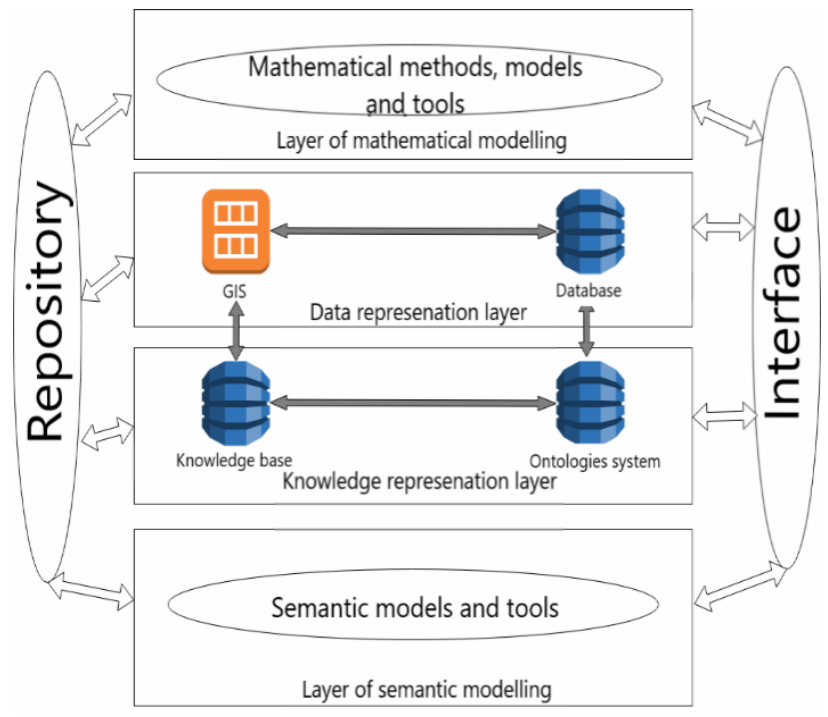

Fig. 4. Architecture of Web-oriented information system

Considering usage of multiagent technology for implementation of some components, it will include following "large" agents:

- Main agent-coordinator - monitors the actions of coordinating agents, contains agent scenarios, based on which builds the order of calling coordinating agents, also controls the actions of the user in the system

- Database agent-coordinator - provides access to the system database 
- Knowledge base and Repository agentcoordinator - provides access to the system database and Repository

- Agent-coordinators of semantic and mathematical modelling tools - control agents responsible for certain modeling tools. Also, each tool is also an agent.

- Agent coordinator of visualization and Geocomponent - provides the ability to visualize the obtained results, for example, in the form of ontologies, cognitive maps, or with the help of map services.

Metadescriptions of information which is presented on all four levels are stored in the Repository. When implementing the user interface, it is supposed to apply the situational calculus [11] and the components of the Knowledge Manipulation Language (KML), which is one of the most important components of the WIS and will be considered in the next section.

\section{CML AND KML}

A. $C M L$

Contingency Management Language (CML) is developed as one of the main components of the Situation polygon. As it was said, it provides functions such as knowledge description, interface functions and integration of other components. CML can be divided into two parts:

- Tools for knowledge manipulation $M$ (support of representations)

- Tools for knowledge description $D$ (description of situations, scenarios, control actions)

Fig. 5 displays CML's metaontology

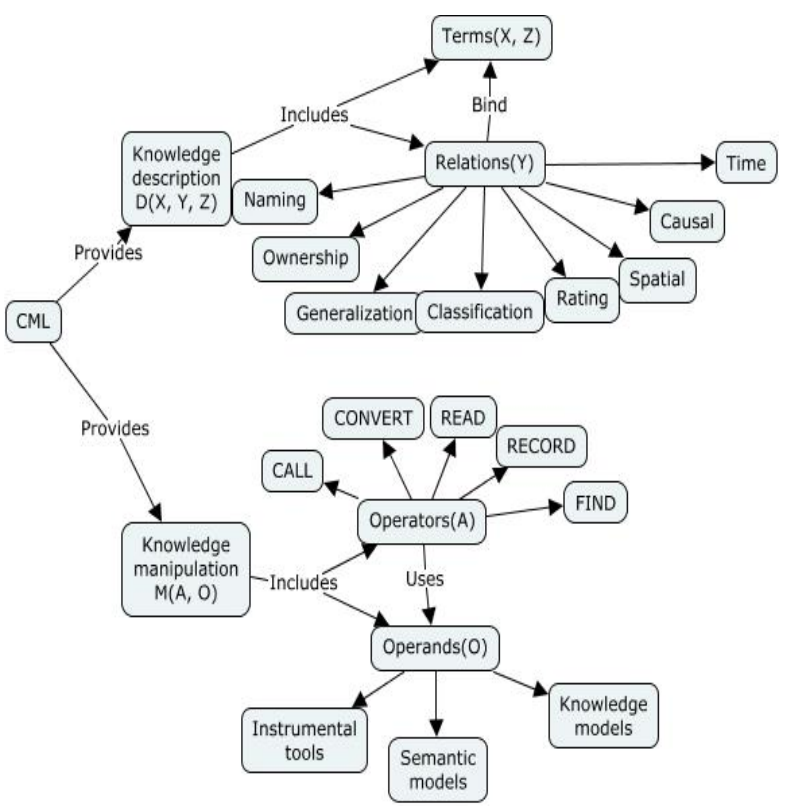

Fig. 5. Metaontology of CML
We propose to use CML as a:

- Language for description and manipulation of knowledge

- Tool for situation classification ("normal", "critical", "emergency")

- As a tool for: calling semantic modelling tools, models conversion (e.g. from ontological to cognitive), calling Geocomponent for 3Dvisulization of the obtained results

- Tool for work with the Repository (storage of knowledge bases and semantic models and operations over them such as search, edit, etc.)

Section, responsible for knowledge description, includes dictionaries of concepts and relations. For knowledge description simple atomic construction (XYZ) is used, where $\mathrm{X}, \mathrm{Z}$ - concepts or names, $\mathrm{Y}$ - relation or action. As for now, CML includes following relations:

- Naming

- Ownership

- Generalization

- Classification

- Rating

- Spatial

- Causal

- Time

For implementation of relations, it is proposed to some concepts of situation calculus [11].

As it can be seen from CML metaontology, part, responsible for knowledge manipulation, includes operators for knowledge manipulation (or action operators). Action is understood as operation, operand — operation parameter. Currently, CML has following operators:

- $\boldsymbol{C A L L}$ - invoke of mathematical and semantic modelling tools

- CONVERT - operation for conversion of objects from one type to another, e.g. conversion of cognitive model to event model

- RECORD, FIND, READ - operations for interaction with the Repository, responsible for knowledge storing, search and extraction from it.

\section{B. $K M L$}

Knowledge Manipulation Language (or KML) is an extension of CML and they are quite similar except operands of knowledge manipulation section. We propose to use KML for:

- Knowledge description and knowledge manipulation

- Interaction with the Repository 
- Tool for invoking the corresponding tools of semantic and mathematical modelling

- Tool for invoking geocomponent (GIS) for 3Dgeovisulization

The mentioned difference between CML and KML mainly is in that KML has more support for mathematical modelling and geoinformation services due to specifics of the project. Fig.6 displays metaontology of KML

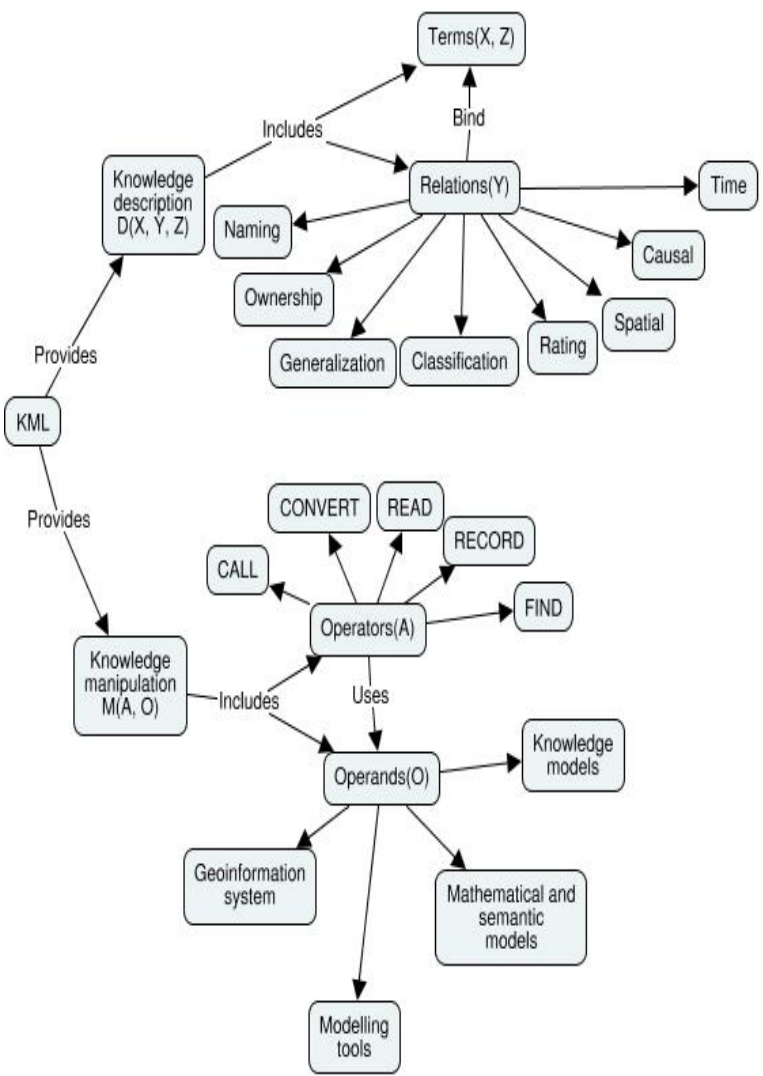

Fig. 6. Metaontology of KML

\section{CONCLUSION}

Concept of situational management proposed by D.A. Pospelov was considered briefly and common scheme for solving the situational management problem was provided. The architecture of typal intelligent DSS for making strategic decisions was shown. Description of agent-service approach is given and implementation of two DSS based on this typal architecture was given Brief description of Contingency Management Language (CML) and Knowledge Manipulation Language (KML) was given. Provided examples of DSS are now under extensive development

\section{ACKNOWLEDGMENT}

Authors thank the staff of the Laboratory of Information Technologies located at ESI SB RAS. Discussions of scientific problems have contributed a lot to formulating the results presented in this article.
This work was partially supported by RFBR grants №19-07-00351, 18-07-00714, 18-37-00271, 18-5781001, 17-07-01341

\section{REFERENCES}

[1] Momoh J., "Smart Grid: Fundamentals of design and analysis" John Wiley and Sons, New York, 2012.

[2] Voropai N.I., Stennikov V.A. "Integrated intelligent energy systems" [Integrirovannie intellektualnie energeticheskie sistemy], in Proceedings of the Russian Academy of Sciences - Energetics, 2014, vol. 1, pp.64-78 in Izvestia RAN. Energetika (in Russian)

[3] "On approval of the activity plan of the Ministry of Energy of the Russian Federation for the period 2019-2024", decree №45 dated 28.01.2019 2018 Available at https://minenergo.gov.ru/view-pdf/13623/92908 (acceseed 15.05.2019) [Ob utverzhdenii plana deyatel'nosti Ministerstva energetiki Rossiyskoy Federatsii na period 2019-2024 godov: prikaz ot 28.01.2019 №45] (in Russian)

[4] Passport of the national program "Digital Economy of the Russian Federation", protocol dated 24.12.2018 №16, 2018. Available http://static.government.ru/media/files/urKHm0gTPPnzJlaKw 3M5cNLo6gczMkPF.pdf (accessed 17.05.2019) [Pasport natsional'noy programmy «Tsifrovaya ekonomika Rossiyskoy Federatsii» : protokol ot 24.12.2018 №16] (in Russian)

[5] Massel L.V., Arshinsky V.L., Massel A.G. "Intelligent computing on the basis of cognitive and event modeling and its application in energy security studies ". Renewable and Alternative Energy: Concept, Methodologies, Tools, and Applications. 2016. pp. 780-787

[6] Pospelov D.A. Situational management. Theory and practice [Situacionnoe upravlenie. Teorija i praktika]. M. Nauka. = Moscow. Science. 1986. 284. (in Russian).

[7] Galperov V.I. Methods, models and algorithms for creaing multiagent systems in energy sector (based on example of task for energy systems state assessment) [Metody, modeli i algoritmy postroeniya mnogoagentnyh sistem $\mathrm{v}$ ehnergetike na primere zadachi ocenivaniya sostoyaniya ehlektroehnergeticheskih system]. Cand. dis. (Tech.) [dis. kand. tekhn. nauk.], Irkutsk, 2017.. (in Russian)

[8] Massel A.G., Galperov V.I., Kuzmin V.R. "Agent-service Approach for Development of Intelligent Decision-making Support Systems". Proceedings of the VIth International Workshop 'Critical Infrastructures: Contingency Management, Intelligent, Agent-Based, Cloud Computing and Cyber Security» (IWCI 2019), 2019, vol.1. pp. 211-215

[9] Massel L.V., Massel A.G. "Language of description and management of knowledge in intelligent system of semiotic type [Jazyk opisaniya i upravleniya znaniyami $\mathrm{v}$ intellektualnoi sisteme semioticheskogo tipa]". XX Baikalskaya Vserossiyskaya konferentsiya "Informatsionnye i matematicheskie tehnologii $v$ nauke $\mathrm{i}$ upravlenii": trudy $=\mathrm{XX}$ Baikal Allrussian conference "Informational and mathematical technologies in science and management": proceedings Vol. 3. Irkutsk. ISEM SO RAN $=$ MESI SB RAS. 2015. pp. 112 - 124 (in Russian)

[10] Massel L.V., Galperov V.I.. "Development of multi-agent systems for the distributed solution of energy problems using agent scenarios". Izvestiya of Tomsk Polytechnic University, 2015; V. 326, T.5, pp. 45-53

[11] Massel L.V., Kuzmin V.R. "Situation calculus as development of semiotic approach to constructing intelligent decision-making support system". Proceedings of the 19th International Workshop on Computer Science and Information Technologies. Germany, Baden-Baden, Vol. 1, 2017, pp. 11-15 